\title{
Research on Green Low Carbon Development in China
}

\author{
Tingfa Zhang ${ }^{1, ~ a ~}$, Jiubin Pang ${ }^{2, b}$ and Peng Sun ${ }^{1, c}$
}

${ }^{1}$ Lanzhou Institute of Chemical Physics, Chinese Academy of Sciences, Lanzhou, China

${ }^{2}$ School of Chemistry and Chemical Engineering, Chongqing University, Chongqing, China

aztfsdu2011@163.com, b pangjb@sdu.edu.cn, ${ }^{c}$ alexsp@163.com

Keywords: Low carbon economy; Energy structure; Energy conservation and emissions reduction; Energy consumption

\begin{abstract}
Under the background of global warming, only the development of low carbon economy can improve the utilization efficiency of existing energy, reduce greenhouse gas emissions, relieve the negative ecological environment impact due to economic growth. China currently has the advantage of the low carbon economy, but traditional pattern of economic development lead to the high energy consumption, high emission and low technical level, energy conservation and emissions reduction task and many other adverse factors, which need to adjust the industrial structure, speed up technological innovation and so on.
\end{abstract}

\section{中国绿色低碳发展对策研究}

\author{
张庭发 $1^{1, \mathrm{a}}$, 庞九涁 $2^{2, \mathrm{~b}}$, 孙鹏 $3^{1, \mathrm{c}}$ \\ 1. 齐鲁师范学院经济与管理学院, 中国山东济南 250200 \\ 2. 山东大学财务部, 中国山东济南 250100 \\ attsdu2011@163.com, ${ }^{\mathrm{b}}$ pangjb@sdu.edu.cn, ${ }^{\mathrm{c}}$ alexsp@163.com
}

\begin{abstract}
摘要: 在全球气候变暖的大背景下, 只有发展低碳经济, 才能提高现有能源的利用效率, 减 少温室气体的排放, 减轻经济增长对生态环境和全球气候的不利影响。中国目前虽已具备发 展低碳经济的优势, 但仍存在传统经济发展方式导致的高能耗、高排放, 技术水平低下, 节 能减排任务艰巨等诸多不利因素, 需要采取调整产业结构, 加快科技创新等相关政策加以应 对。
\end{abstract}

关键词：低碳经济; 能源结构;节能减排; 能源消费

\section{1. 低碳经济发展的背景}

根据世界气象组织（WMO）发布《温室气体公报》显示，2014 年全球大气中主要温室气体的 浓度再次达到新高。其中, 二氧化碳、甲烷、氧化亚氮的平均浓度等分别比 1750 年工业化革 命前增加了 43\%、154\%和 21\%。并且 2013 至 2014 年甲烷和氧化亚氮的增量平均高于 2012 至 2013 年的观测结果和过去十年平均增速。温室气体使得地球辐射强迫水平从 1990 年到 2014 年上升了 36\%。

2014 年由于化石燃料燃烧和水泥生产的原因, 大气二氧化碳达到工业革命前水平的 143\%。上 个十年中, 大气二氧化碳的平均增加相当于人类活动排放的约 $44 \%$, 其余约 $56 \%$ 被海洋和陆地 生物圈吸收。化石燃料带来的高能耗、高排放和高污染，已不能支持人类的可持续发展。与 此同时，化石燃料的稀缺性、不可再生性，使得提高能源使用效率，调整能源结构成为必然。 在碳排放量高速增长和化石能源不可持续的时代背景下, 发展低碳经济, 加快经济发展模式 转变刻不容缓。从 1992 年达成的《联合国气候变化框架公约》到 1997 年《京都议定书》的 签订，从 2009 年的哥本哈根世界气候大会到 2014 年的利马世界气候大会，世界各国及各组 
织对二氧化碳等温室气体的关注日益强烈，对节能减排、发展低碳经济, 走绿色化的呼声也日 益高涨。

\section{2. 中国能源发展现状}

2.1. 能源消费现状

我国能源消耗量处于逐步上升状态，尽管人均能源资源拥有量处于世界比较低水平。2013 年 中国的能源消费增长速度为 $4.7 \%$, 低于过去十年 $8.6 \%$ 的平均水平, 但是仍占全球能源消费量 的 22. 4\%, 成为世界上最大的能源消费国（图 1)。2014 年我国一次能源消耗结构中，煤炭仍 占据大幅比重, 高达 $66 \%$, 而清洁能源却只占了很小比重（水电占 $8.1 \%$, 核电占 $1 \%$, 可再生 能源占 1.8\%)（图 2)。这种以煤为主的高碳能源结构不仅对环境造成巨大的威胁, 更是制约 我国经济发展模式的转变。中国的温室气体与以煤炭为主的能源结构有关。

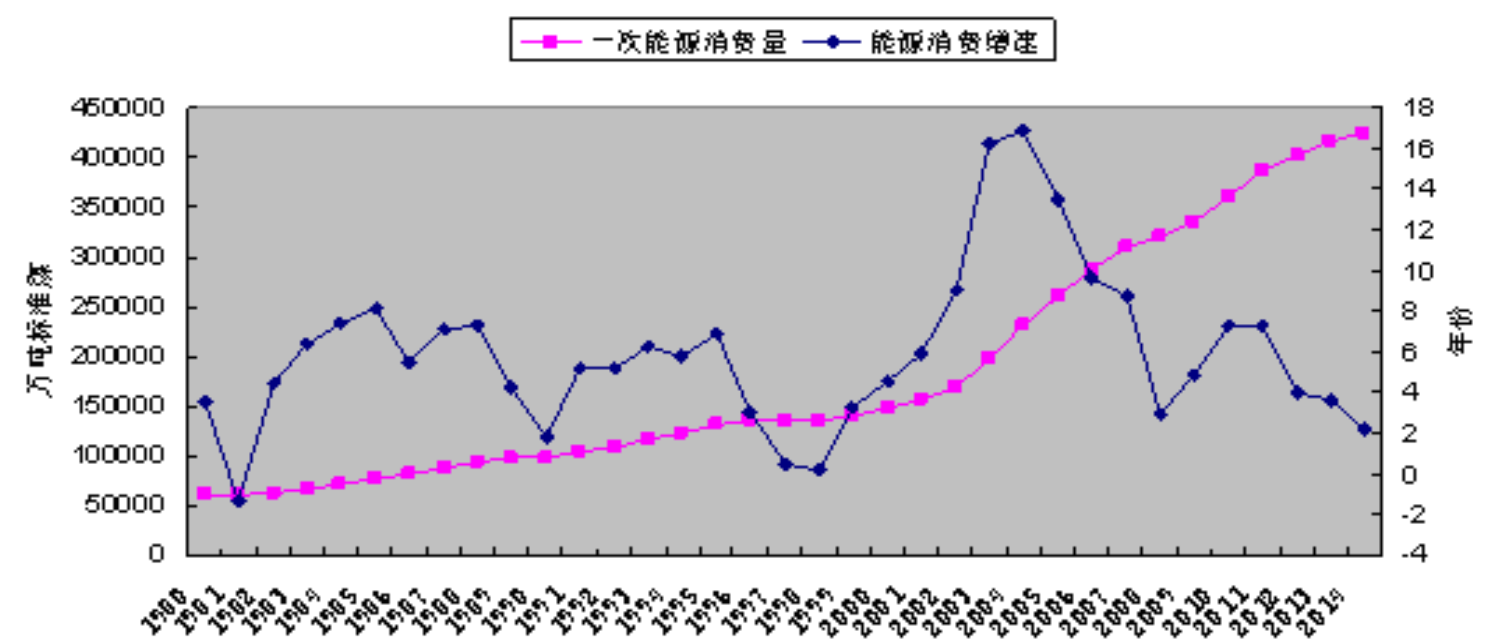

图 1 中国 1980-2014 年一次能源消费量和能源消费增速

作为发展中国家，我国在经济发展中所面临的形势是相当严峻的。不仅与世界其他国家一样 面临着气候等生态问题的共性, 更具有我国能源问题的特性。这体现在一方面, 高污染、高 排放使得我国生态环境遭到严重破坏; 另一方面, 高能耗使我国能源面临危机, 经济效率受 到挑战。因此, 这就更加体现出节能减排和低碳发展对我国经济发展的重要性, 低碳经济是 我国发展的必然选择。

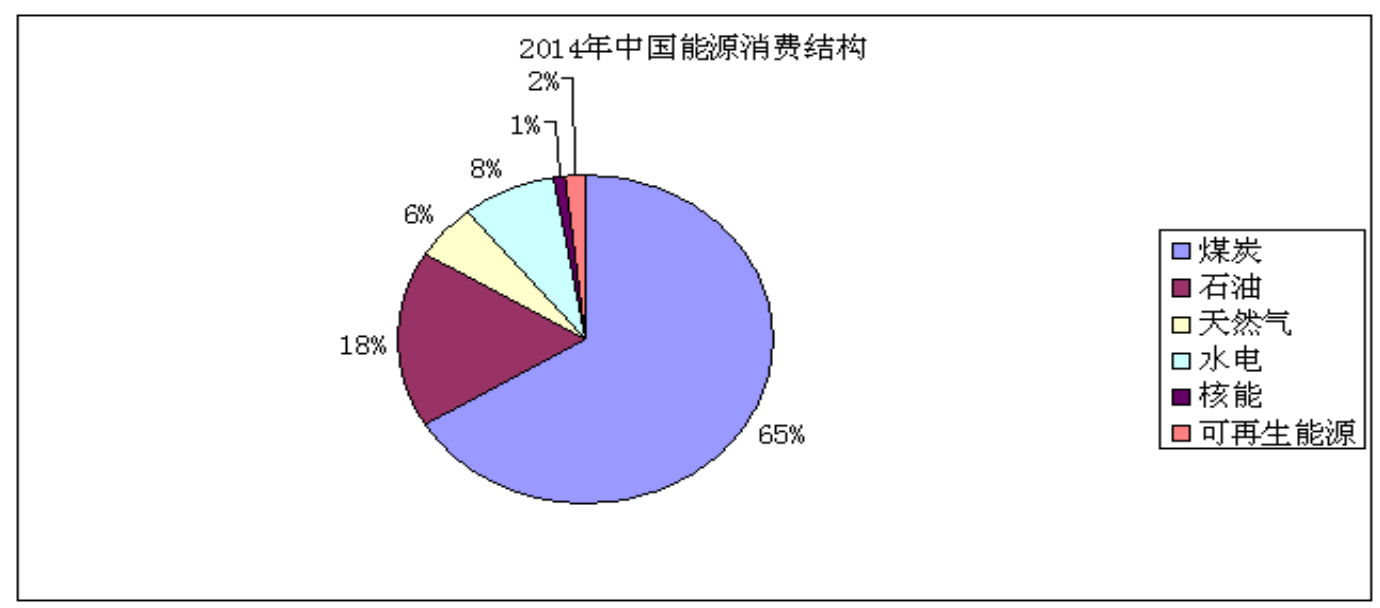

图 22014 年我国能源结构 


\section{2. 我国碳排放状况}

典型的碳基能源经济模式, 使我国二氧化碳排放强度相对较高。根据研究统计结果现实, 我 国一次能源消费导致的二氧化碳排放量, 由 1995 年的 78678 万吨碳增长到 2006 年的 146919 万吨碳, 年均增长率 $5.84 \%$, 人均二氧化碳年排放量也由 0.62 吨碳/人增加到 1.12 吨碳/人。 2005-2011 年全球新增二氧化碳排放量中, 我国所占比重达到 60\%以上。2011 年我国二氧化 碳排放量达到 80 亿吨, 占世界总排放量的四分之一强, 已经超过美国跃居世界首位。

因此，我国节能减排形势非常严峻，压力巨大。如果继续采用原来的传统技术，对高碳产业 不加限制, 那么在以后需要承诺减排义务时, 就可能被这些高碳产业所 “锁定”。所以, 我国 必须摆脱对化石能源的过度依赖, 不断提高我国的低碳技术和产品的竞争力, 逐步向低碳产 业转型。

2006 年 12 月, 我国正式发布第一份《气候变化国家评估报告》提出中国要走低碳经济的发 展道路。2009 年 6 月, 社科院发布《城市蓝皮书: 中国城市发展报告 (NO. 2) 》, 指出低碳经 济将引领未来城建趋势, 促进低碳经济发展正在成为各级部门决策者的共识, 也是拯救全球 变暖的关键性方案。

可见，在低碳经济逐渐受到世界各国重视的背景下，我国也正逐步跟上时代步伐，通过政策 性的文件和措施, 指引社会各阶层从思想上和行动上加入到发展低碳经济的行列中来, 从而 实现社会经济的转型, 保持持续的国际竞争力和发展动力。

\section{3. 低碳经济发展存在的问题}

3.1. 能源消费总量大、增速快

我国一次能源消费总量由 2001 年的 15.04 亿吨标准煤增长到 2014 年的 4.26 亿吨标准煤, 年 均增速达到 5\%左右 (图 1)。

3.2 环境污染日益严重

2014 年, 我国二氧化硫排放总量同比下降 3. 4\%, 但依然达到 1974.4 万吨, 。全国化学需氧量 排放总量同比下降 $2.47 \%$, 但是到了 2294.6 万吨。氨氮排放总量为 238.5 万吨, 氮氧化物排 放总量为 2078 万吨, 四项污染物排放量与 2010 年相比, 分别下降 $12.9 \% 、 10.1 \% 、 9.8 \%$ 、和 8. $6 \%$ 。

3. 3 . 行业能源消费很不合理

我国产业结构中占据主导地位的仍是第二产业, 占到了 $46.8 \%$, 从数据上看, 第二产业和第 三产业差距不大, 但是从行业能源消耗角度上看却有着明显的差别, 第二产业的能源消耗占 到了总能源消耗的七成以上，并且基本上都是高污染、高消耗的生产模式。

\section{4. 低碳经济发展的对策}

4.1. 环境污染治理需要进一步加大投入

作为制约我国低碳经济发展的主要因素, 环境治理保护资金的持续投入是极其重要的, 进而 才能增强治理环境污染的能力。同时，应该提高治理环境污染的科技水平。

4.2. 调整产业结构

第二产业污染环境严重, 主要是由于其能源消费量非常大, 因此调整产业结构成为必然。首 先必须淘汰落后技术大力发展小规模现代服务业, 其次, 必须创造服务业品牌, 在此基础上 才能提升我国产业结构及其发展水平。

4.3. 优化能源结构, 提高能源利用率

必须改变我国能源消费中煤炭消费为主的局面。因此需要大力开发和利用新型能源, 比如风 能、电能、海洋能源、核能、光能、生物能源等, 实现经济可持续发展。 


\section{参考文献}

[1] 邓楠. 中国的可持续发展与绿色经济—-2011 中国可持续发展论坛主旨报告 [J]. 中国人 口.资源与环境. 2012, 22(01): 1-3.

[2] 钱洁, 张勤. 低碳经济转型与我国低碳政策规划的系统分析, 《中国软科学》, 2011(4):22-28.

[3] 陈诗一.中国各地区低碳经济转型进程评估，经济研究, 2012(8):32-44.

[4] 刘成浩, 何冰雁. 我国低碳经济转型下的情景分析和路径选择, 上海管理科学, 2014, 36(5):5-9.

[5] K Parikh. Sustainable development and low carbon growth strategy for India[J]. Energy, 2012, 40(1):31-38.

[6] Furman, J.L., Porter, M.E., Stern, S. The determinants of national innovative capacity [J]. Research Policy, 2002,31(6):899-933.

[7] UK Rout. Prospects of India's energy and emissions for a long time frame[J]. Energy Policy, 2011,39(9):5647-5663.

[8] P Balachandra, D Ravindranath, NH Ravindranath. Energy efficiency in India: Assessing the policy regimes and their impacts[J]. Energy Policy, 2010,38(11):6248-6438.

[9] Hu, X., Murgovski, N., Johannesson, L., Egardt, B. Energy efficiency analysis of a series plug-in hybrid electric bus with different energy management strate gies and battery sizes[J]. Energy, 2013, 111(11):1001-1009.

[10] Yang, Z., Kang, L., Niu, Q., et al. A self-learning TLBO based dynamic eco nomic/environmental dispatch considering multiple plug in electric vehicle loads[J]. Cle. Energ, 2014, 2 (4), 298-307.

\section{References}

[1] Nan Deng. Sustainable development and green economy in China---2011 China Sustainable Development Forum keynote Report [J]. China's population. Resources and environment. 2012, 22(01): 1-3

[2] Jie Qian, Qin Zhang. Low carbon economy transformation and the system analysis of China's low carbon policy planning, China Soft science, 2011 (4): 22-28

[3] Shiyi Chen. Evaluation of low carbon economy transition process in China, economic research, 2012 (8):32-44

[4] Haocheng Liu, Bingyan Dong. Scenario analysis and path selection of China's low carbon economy transition, Shanghai Management Science, 2014, 36 (5): 5-9

[5] K Parikh. Sustainable development and low carbon growth strategy for India[J]. Energy, 2012, 40(1):31-38.

[6] Furman, J.L., Porter, M.E., Stern, S. The determinants of national innovative capacity [J]. Research Policy, 2002, 31 (6):899--933.

[7] UK Rout. Prospects of India's energy and emissions for a long time frame[J]. Energy Policy, 2011,39(9):5647-5663.

[8] P Balachandra, D Ravindranath, NH Ravindranath. Energy efficiency in India: Assessing the policy regimes and their impacts[J]. Energy Policy, 2010,38(11):6248-6438.

[9] Hu, X., Murgovski, N., Johannesson, L., Egardt, B. Energy efficiency analysis of a series plug-in hybrid electric bus with different energy management strate gies and battery sizes[J]. Energy, 2013, 111(11):1001-1009. 
[10] Yang, Z., Kang, L., Niu, Q., et al. A self-learning TLBO based dynamic eco nomic/environmental dispatch considering multiple plug in electric vehicle loads[J]. Cle. Energ, 2014, 2 (4), 298-307.

作者简介: 张庭发 (1971一), 男, 山东东营, 副教授, 主要研究方向: 能源经济, E-mai1: ztfsdu2011@163.com 